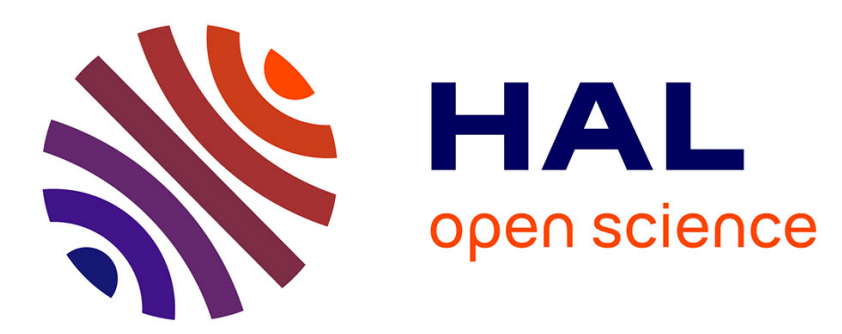

\title{
Evaluation of lightning induced magnetic fields inside reinforced concrete buildings
}

\author{
C. Miry, E. Amador, P. Duquerroy, E. Bachelier, D. Prost, F. Issac
}

\section{To cite this version:}

C. Miry, E. Amador, P. Duquerroy, E. Bachelier, D. Prost, et al.. Evaluation of lightning induced magnetic fields inside reinforced concrete buildings. XII International Symposium on Lightning Protection (SIPDA), Oct 2013, BELO HORIZONTE, Brazil. hal-01057948

\section{HAL Id: hal-01057948 \\ https://hal-onera.archives-ouvertes.fr/hal-01057948}

Submitted on 25 Aug 2014

HAL is a multi-disciplinary open access archive for the deposit and dissemination of scientific research documents, whether they are published or not. The documents may come from teaching and research institutions in France or abroad, or from public or private research centers.
L'archive ouverte pluridisciplinaire HAL, est destinée au dépôt et à la diffusion de documents scientifiques de niveau recherche, publiés ou non, émanant des établissements d'enseignement et de recherche français ou étrangers, des laboratoires publics ou privés. 


\title{
Evaluation of lightning induced magnetic fields inside reinforced concrete buildings
}

\author{
C. Miry, E. Amador, P. Duquerroy \\ EDF R\&D \\ Moret sur Loing, France
}

\author{
E. Bachelier, D. Prost, F. Issac \\ ONERA, The French Aerospace Lab \\ F-31055, Toulouse, France
}

$$
I(t)=781\left(e^{-38393 t}-e^{-353962 t}\right),(1)
$$

\begin{abstract}
In this paper, the shielding effectiveness of a reinforced concrete building against lightning induced effects is analyzed. Measurements of magnetic fields induced inside such a structure stressed by a lightning type of aggression are used to setup numerical models of the building with three distinct methods: the method of moments (MoM) with the CDEGS software, the Transmission Line Method (TLM) with CST's MWS software and LR equivalent circuit simulation technique with ONERA's LIRIC computer code. Once the limitations of the numerical models are identified, they are used to study the effect of a standard lightning strike in terms of magnetic fields inside the structure.
\end{abstract}

Keywords-component: lightning currents, magnetic field, reinforced concrete buildings, numerical analysis

\section{INTRODUCTION}

When a building is struck by lightning, the propagating lightning current induces over-voltages and electromagnetic fields inside the structure. Steel mesh of reinforced concrete buildings is often used as part of the structure lightning protection system (LPS) [1-4]. This paper proposes to evaluate, using numerical simulations, the shielding effectiveness of a steel reinforced concrete building. Previous measurements of magnetic fields induced inside such a structure stressed by a lightning type of aggression [4] are used as a reference case to compare three different numerical methods: the method of moments (MoM) with the CDEGS software [5], the Transmission Line Method (TLM) with CST's MWS software [6] and LR equivalent circuit simulation technique with ONERA's LIRIC computer code [10]. First, a current injection, using a generator outside the building reproducing the measurements, is considered to validate a simplified building model. Then, a standard lightning current, using IEC 62305-1 definitions [8], is taken into account to evaluate induced magnetic fields in the case of a more realistic lightning strike.

\section{COMPUTATIONAL APPROACH}

\section{A. Building studied and measurements}

Previous magnetic fields measurements have been done inside a reinforced concrete building made of several floors. The only opening of the building is an aperture located at the mast floor level [4]. The top of the structure has been stressed using a generator located outside, on the ground floor, several meters away from the structure, as illustrated in Fig.1. The injected current, illustrated in Fig.2, is represented by the following equation:
Its spectrum is similar to the bi-exponential lightning signal's spectrum.

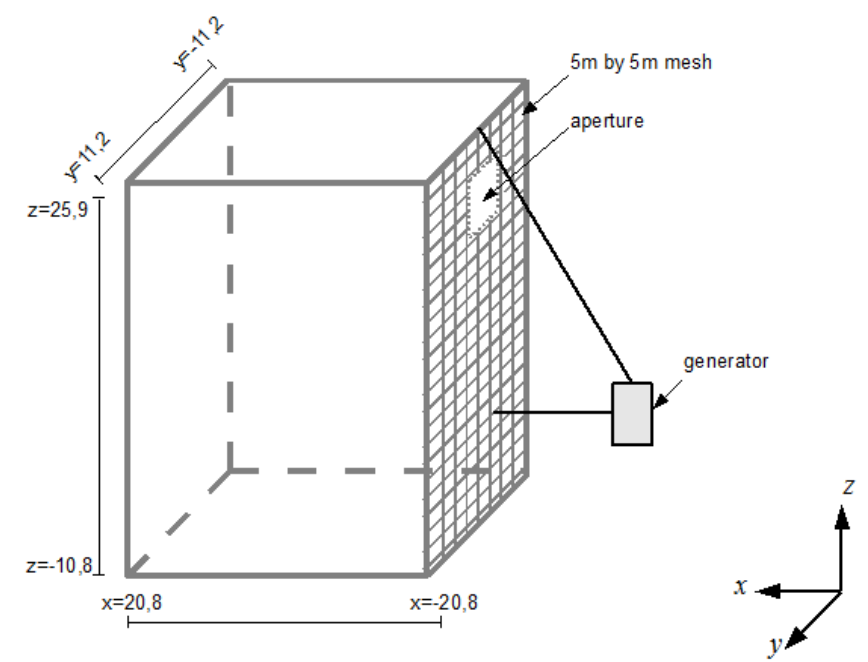

Figure 1 : Structure description (the $1 \mathrm{~m}$ by $1 \mathrm{~m}$ mesh is not represented on all the faces of the structure as well as the soil for reading convenience)

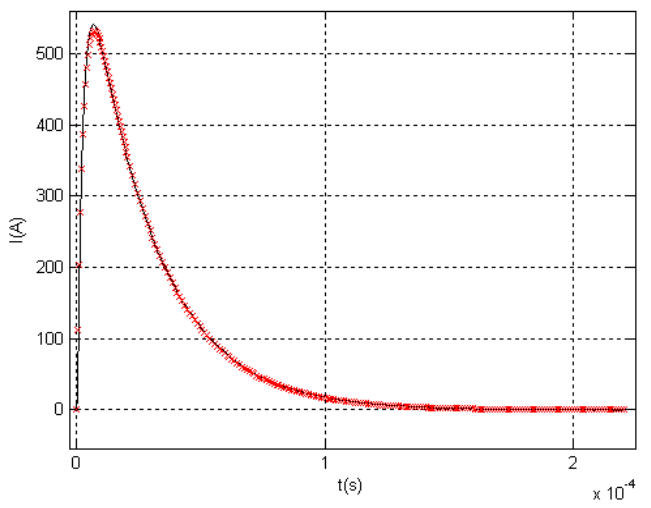

Figure 2 : Injected current inside the building

The magnetic field is measured at different points located on the last two floors. Results in terms of maximum are given in Table 1 for the most relevant positions. Point $\mathrm{P}_{1}$ is located on the last floor, close to the aperture. Point $\mathrm{P}_{2}$ is at the same position but a level below. Points $\mathrm{P}_{3}$ and $\mathrm{P}_{4}$ are located on the 
same floor as $\mathrm{P}_{2}, \mathrm{P}_{3}$ is farther from the wall and $\mathrm{P}_{4}$ is close to a corner (two perpendicular components of the magnetic field are measured).

Table 1 : Magnetic fields measurements

\begin{tabular}{|l|l|c|}
\hline Point & Coordinates (m) & $\begin{array}{c}\text { Maximum measured } \\
\text { magnetic field (A/m) }\end{array}$ \\
\hline $\mathrm{P}_{1}$ & $(-20.5 ; 7.7 ; 20.6)$ & $\mathrm{H}_{\mathrm{y}}=0,606$ \\
\hline $\mathrm{P}_{2}$ & $(-20.5 ; 7.7 ; 14.6)$ & $\mathrm{H}_{\mathrm{y}}=0,103$ \\
\hline $\mathrm{P}_{3}$ & $(-19.4 ; 7.7 ; 14.6)$ & $\mathrm{H}_{\mathrm{y}}=0,085$ \\
\hline $\mathrm{P}_{4}$ & $(-20.5 ; 3.6 ; 14.6)$ & $\mathrm{H}_{\mathrm{x}}=0,035$ \\
& & $\mathrm{H}_{\mathrm{y}}=0,12$ \\
\hline
\end{tabular}

Figures 3 and 4 show measured magnetic field waveforms. Measured signals in the building are generally slower than injected current. The several layers of steel mesh in the walls act as a low-pass filter for the excitation current. The measured response at point $\mathrm{P}_{1}$, close to the aperture, does not exhibit this low-pass behavior. Thus we can assume that the magnetic field measured at $\mathrm{P}_{1}$ is mainly due to the direct contribution of the injected current so the high-frequency part of the signal is more visible.

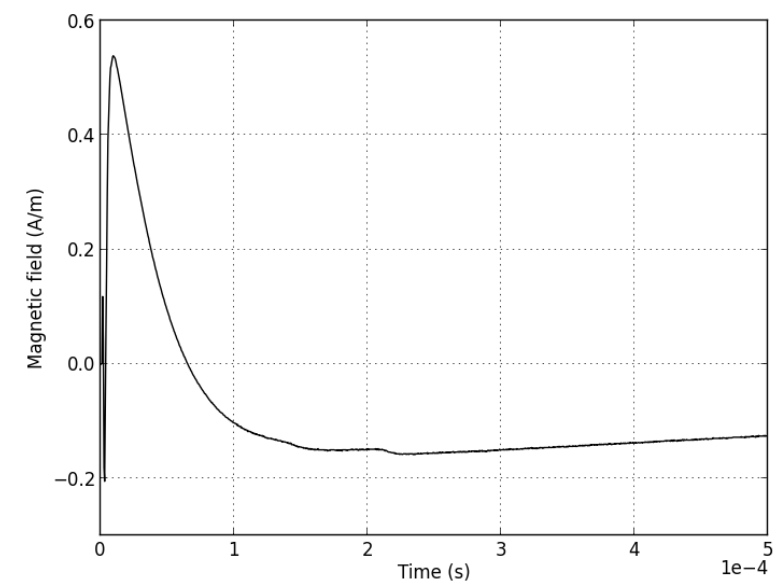

Figure 3 : Measured magnetic field at $\mathbf{P}_{1}$

\section{B. Equivalent model}

The building dimensions are $41.6 \mathrm{~m}$ by $22.4 \mathrm{~m}$ by $36.7 \mathrm{~m}$. In order to reduce the model complexity, the walls of the building are modeled with one layer of a $5 \mathrm{~m}$ by $5 \mathrm{~m}$ steel mesh, as shown in Fig.1. The two lowest floors are located under the ground. The ground is modeled using a uniform material with a $100 \Omega . m$ resistivity.

The density of the reinforcement steel in a real wall of the building is much larger than the building model used in our simulations. Thus the simulated shielding of the wall is less effective than with a real wall and the magnetic field levels computed are larger than the experimental results.
Moreover, a $5 \mathrm{~m}$ by $5 \mathrm{~m}$ steel mesh does not allow taking into account the $2 \mathrm{~m}$ by $3 \mathrm{~m}$ aperture on the last floor. Thus particular attention will be drawn when comparing measured and calculated results at point $\mathrm{P}_{1}$ as it is located close to the aperture.

Three different numerical techniques briefly described below are used to compute the magnetic fields inside the structure.

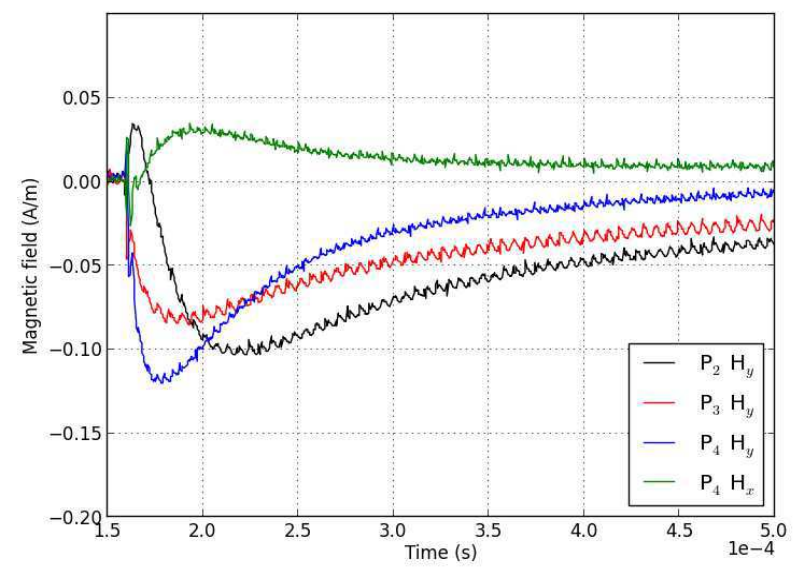

Figure 4 : Measured magnetic fields at $P_{2} P_{3}$ and $P_{4}$

\section{Numerical techniques}

The CDEGS computer code is based on the method of moments. It solves Maxwell's equations in the frequency domain. The frequency response of the structure is first determined, and then time domain solutions are obtained using inverse Fourier transformation.

The CST MWS solver used in this analysis is based on the TLM method. Equations are solved in time domain. Thus maximum magnetic field levels are directly obtained.

The so-called thin-wire approach is used to model the steel reinforcement wires with both techniques.

As an alternative to the heavy full-wave modeling approach, the LIRIC (LIghtning Resistive - Inductive Computation) circuit simplified approach is also used. It consists in building and solving an equivalent electric circuit model made of wire conductors connected by nodes and describing the relative positions of the main constitutive parts of the whole 3D geometry under study.

The soil is represented in the CDEGS model only. For the experimental configuration with the external generator, its presence (or its absence) does not affect the magnetic field computed at the higher floor levels where the measurements and the computation were done. 


\section{RESULTS AND DISCUSSION}

\section{A. Comparison of measured and calculated results}

The aim of the first step is to evaluate the approximation of the previously described simplified model described in Fig.1 compared to experimental data.

The excitation is realized using an external generator delivering the Eq. 1 current represented in Fig. 2 at the top of the building as illustrated in Fig. 1. The configuration is similar to the measurements. Figures 5 and 6 show a comparison of calculated magnetic fields respectively at $\mathrm{P}_{1}$ and $\mathrm{P}_{2}$. Maximum magnetic fields are summed up in Table 2. The different numerical techniques give similar results. Besides, Figures 7, 8 and 9 show the global behavior of the building on the last floor. The different numerical methods give similar results again. This validates the three numerical approaches. Thus, for this kind of simplified model the circuit simulation is a good alternative as it takes only a few minutes of computation, compared to several hours for full-wave modeling.

Measured responses are generally slower than calculated ones except for point $\mathrm{P}_{1}$. As explained in paragraph II.A, the several layers of steel mesh act as a low-pass filter in a real wall. We cannot reproduce such a behavior with only one layer of a $5 \mathrm{~m}$ by $5 \mathrm{~m}$ steel mesh. Using a thin panel with equivalent thickness and conductivity to observe a realistic response could improve the results.

Modeling the building with one layer of $5 \mathrm{~m}$ by $5 \mathrm{~m}$ steel mesh is highly conservative in terms of induced magnetic field. As shown in [11], the magnetic field induced inside a building is directly dependent of the width of the building mesh. Thus, an error factor can be evaluated for the simple mesh model and taken into account in the second step in order to be closer to the expected lightning induced magnetic field levels. We observe that dividing calculated results by an error factor of 10 will still lead to majoring results compared to measurements except for point 1 which is in front of the temporary aperture. Besides, we remind that the current distribution observed with an external generator injection is not equivalent to the current distribution induced by a real lightning strike. First, it is necessary to evaluate the magnetic field levels with a more realistic lightning strike.

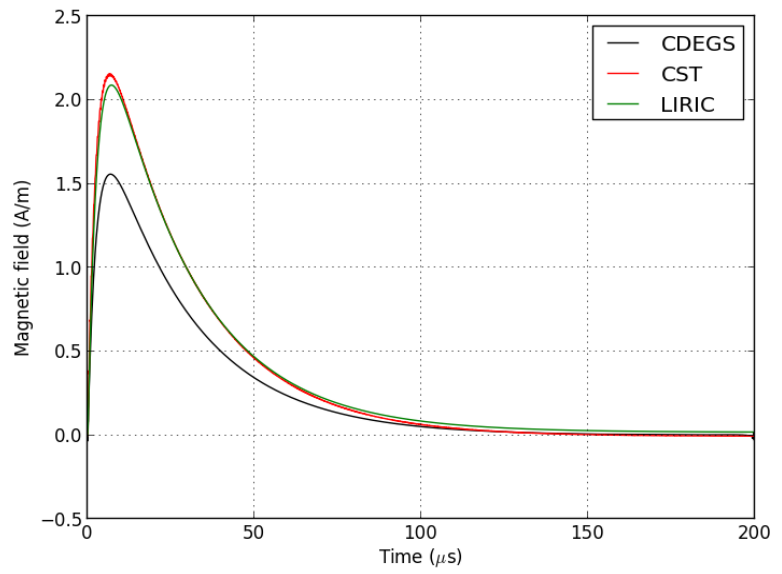

Figure 5 : Calculated magnetic field at $\mathbf{P}_{1}$

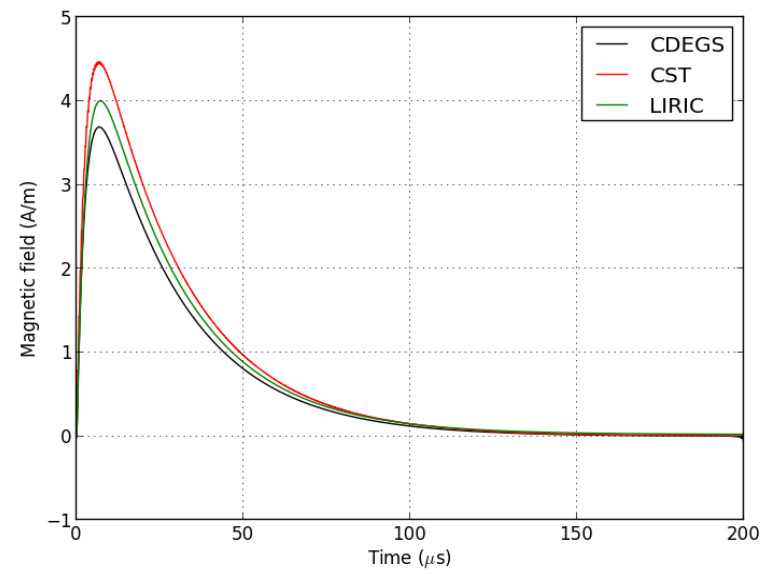

Figure 6 : Calculated magnetic field at $\mathbf{P}_{2}$

Table 2 : Comparison of maximum calculated magnetic fields

\begin{tabular}{|l|c|c|c|}
\hline Point & $\begin{array}{c}\text { CST results } \\
(\mathbf{A} / \mathbf{m})\end{array}$ & $\begin{array}{c}\text { CDEGS results } \\
(\mathbf{A} / \mathbf{m})\end{array}$ & $\begin{array}{c}\text { LIRIC results } \\
(\mathbf{A} / \mathbf{m})\end{array}$ \\
\hline $\mathrm{P}_{1}$ & $\mathrm{H}_{\mathrm{y}}=2,15$ & $\mathrm{H}_{\mathrm{y}}=1,56$ & $\mathrm{H}_{\mathrm{y}}=2,08$ \\
\hline $\mathrm{P}_{2}$ & $\mathrm{H}_{\mathrm{y}}=4,46$ & $\mathrm{H}_{\mathrm{y}}=3,69$ & $\mathrm{H}_{\mathrm{y}}=4$ \\
\hline $\mathrm{P}_{3}$ & $\mathrm{H}_{\mathrm{y}}=1,57$ & $\mathrm{H}_{\mathrm{y}}=1,04$ & $\mathrm{H}_{\mathrm{y}}=1,52$ \\
\hline $\mathrm{P}_{4}$ & $\mathrm{H}_{\mathrm{x}}=3,86$ & $\mathrm{H}_{\mathrm{x}}=4,73$ & $\mathrm{H}_{\mathrm{x}}=3,58$ \\
& $\mathrm{H}_{\mathrm{y}}=11,42$ & $\mathrm{H}_{\mathrm{y}}=10,48$ & $\mathrm{H}_{\mathrm{y}}=10,83$ \\
\hline
\end{tabular}

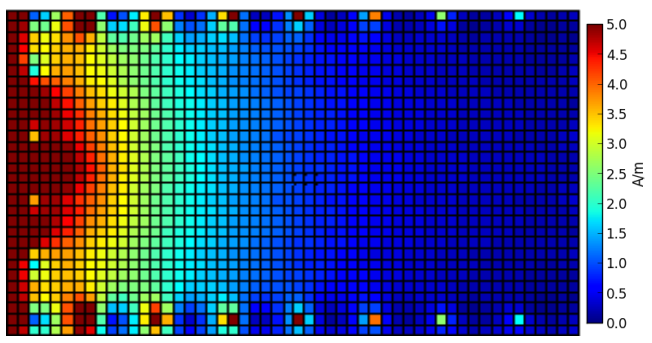

Figure 7 : Maximum magnetic field for $\mathrm{z}=20.2 \mathrm{~m}$ (LIRIC)

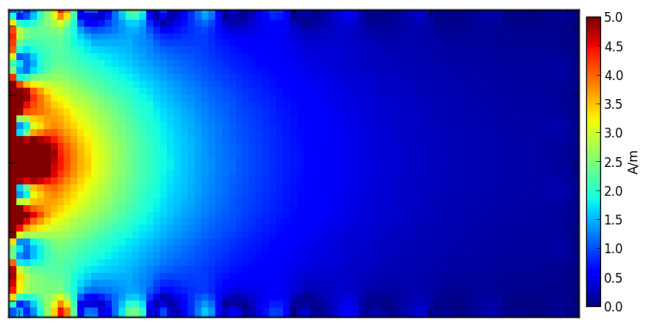

Figure 8 : Maximum magnetic field for $\mathrm{z}=20.2 \mathrm{~m}(\mathrm{CST})$ 


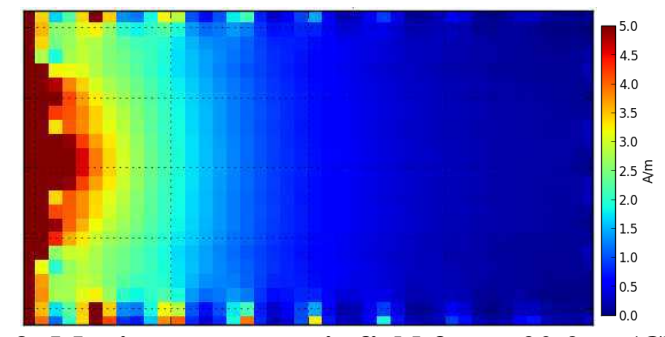

Figure 9: Maximum magnetic field for $\mathrm{z}=20.2 \mathrm{~m}$ (CDEGS)

\section{B. Comparison of an external generator injection and a standard lightning strike}

The aim of this step is to compare the impact of the current distribution induced by a real lightning strike and an external generator.
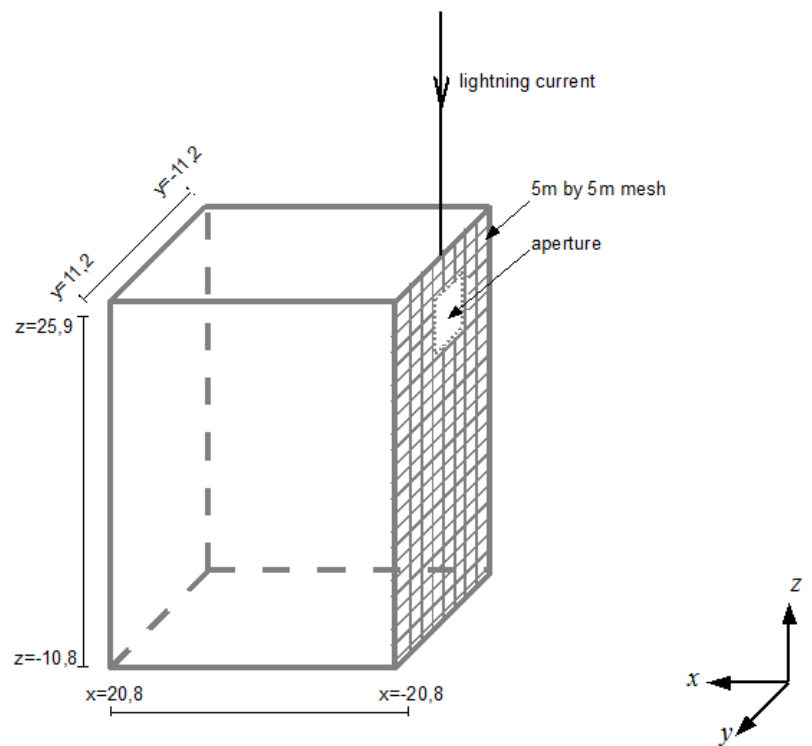

Figure 10: Structure description for the lightning stroke (the $1 \mathrm{~m}$ by $1 \mathrm{~m}$ mesh is not represented on all the faces of the structure as well as the soil for reading convenience)

The generator defined in the previous case is removed and a lightning model is used to simulate a lightning stroke on the roof of the building as shown in Fig.10. The current injected corresponds to the first short stroke described in IEC 62305-1 [8] (cf Figure 11). We choose the most severe standard waveform in terms of maximum magnetic field level. It can be represented by the Heidler function:

$$
I(t)=\frac{I_{0}}{k} \frac{\left(t / T_{1}\right)^{n}}{1+\left(t / T_{1}\right)^{n}} e^{-t / T_{2}}(2)
$$

With $k=e^{-\left(T_{1} / T_{2}\right)\left(n T_{2} / T_{1}\right)^{1 / n}}, \mathrm{I}_{0}=200 \mathrm{kA}, \mathrm{T}_{1}=19 \mu \mathrm{s}, \mathrm{T}_{2}=485$ $\mu \mathrm{s}, \mathrm{k}=0.93$ and $\mathrm{n}=10$.

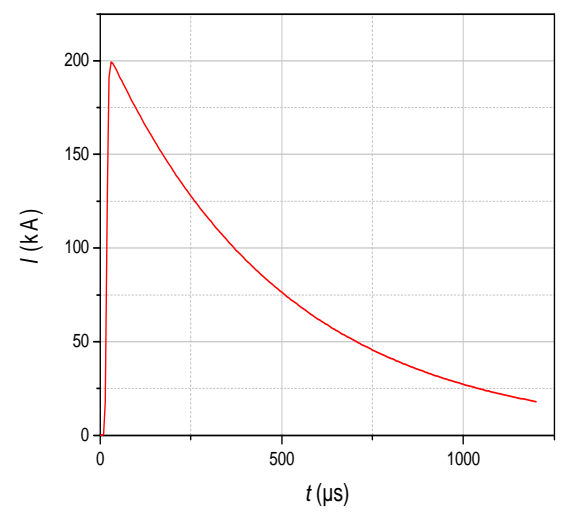

Figure 11 : Lightning first short stroke injected current

Simulations are done with CDEGS using the model described in paragraph II.B. Fig. 12 and 13 give the maximum magnetic field level in a horizontal plane $(Z=20.2 \mathrm{~m})$ corresponding to the upper floor (the most impacted with the different configurations). Fig. 14 and 15 give the magnetic field level in a vertical plane $(\mathrm{X}=-19.4 \mathrm{~m})$ located $1.4 \mathrm{~m}$ from the wall.

As far as field amplitudes is concerned, magnetic field is much higher in the case of a lightning strike as it is directly proportional to the injected current. As far as current distribution inside the building is concerned, Fig. 12 and 14 (with the external generator) show that the highest levels are concentrated in an area close to the injection wire unlike in Fig. 13 and 15 (lightning channel on the roof) where the magnetic field is spread more homogeneously. This difference can be explained easily: with the external generator position and the current loops back to the generator (at the $\mathrm{z}=0 \mathrm{~m}$ level); most of the current is drained directly through the vertical wires close to the generator, therefore the injection wire directly radiates inside the building. By defining an error factor (III-A) from the measurement data and the simulations results with the generator configuration, we have a majoring configuration (the field are less homogenous) compared to a standard lightning channel.

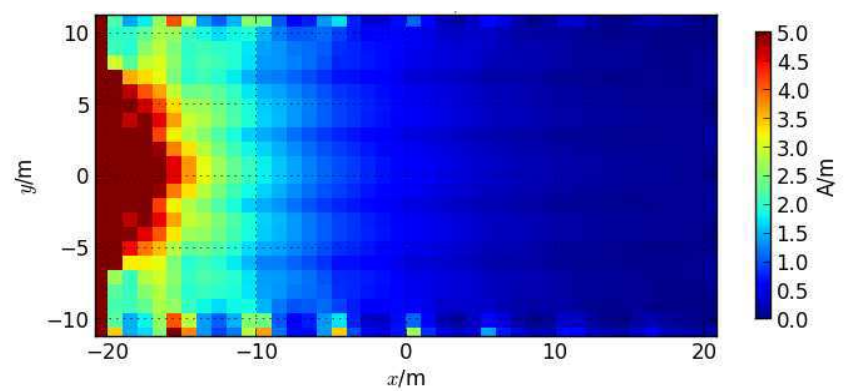

Figure 12 : Maximum magnetic field for $\mathrm{z}=20.2 \mathrm{~m}-$ external generator (CDEGS) 


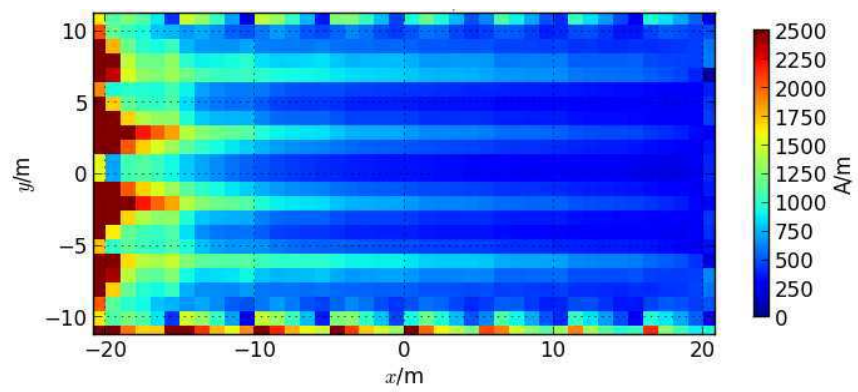

Figure 13: Maximum magnetic field for $\mathrm{z}=20.2 \mathrm{~m}-$ lightning stroke (CDEGS)

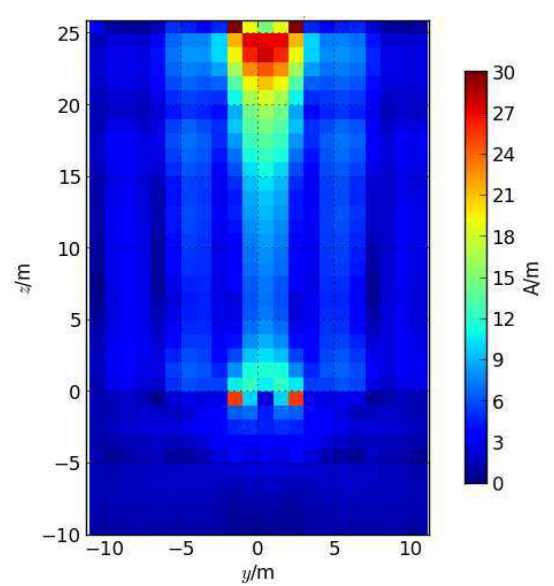

Figure 14 : Maximum magnetic field for $x=-19.4 \mathrm{~m}-$ external generator (CDEGS)

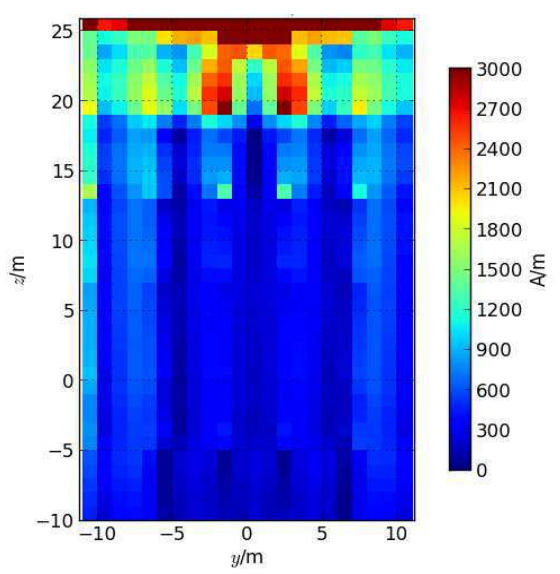

Figure 15 : Maximum magnetic field for $x=-19.4 \mathrm{~m} \mathrm{-}$ lightning stroke (CDEGS)

\section{Evaluation of magnetic fields induced by a standard lightning strike}

The aim of the third step is to evaluate the expected magnetic field induced levels after a lightning strike. The error factor defined in paragraph III.B is applied to the computed magnetic field with lightning strike configuration. Magnetic field levels are compared to the severity degrees given in [9]. From Fig. 17 we can assume that the first severity degree $(\mathrm{H}<100 \mathrm{~A} / \mathrm{m})$ is respected 2 meters away from the walls on the whole second to last floor $(\mathrm{z}=14.6 \mathrm{~m})$. On the upper floor (Fig.16), we need to be 10 meter away from the impacted wall to respect this severity degree. However, the observed magnetic field distribution (maximum levels in front of each conductor) is mainly due to the building model. With a more realistic building model the maximum magnetic field distribution in front of the impact would be smaller and the $100 \mathrm{~A} / \mathrm{m}$ limit would be closer to the wall.

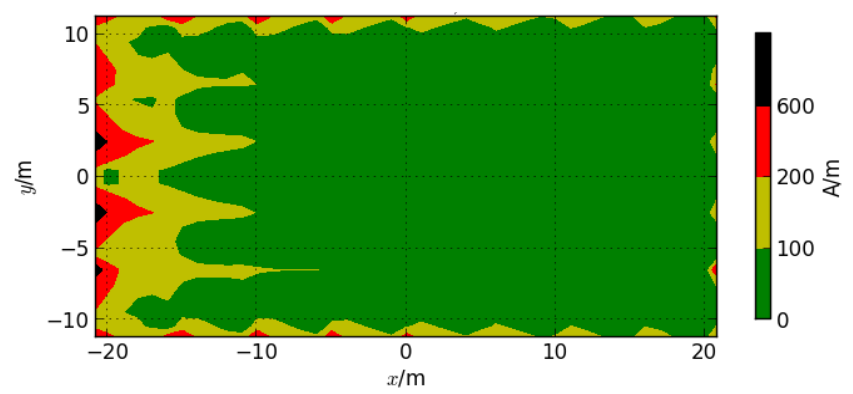

Figure 16 : Magnetic field inside the upper floor level $(\mathrm{z}=\mathbf{2 0 . 2} \mathrm{m})$

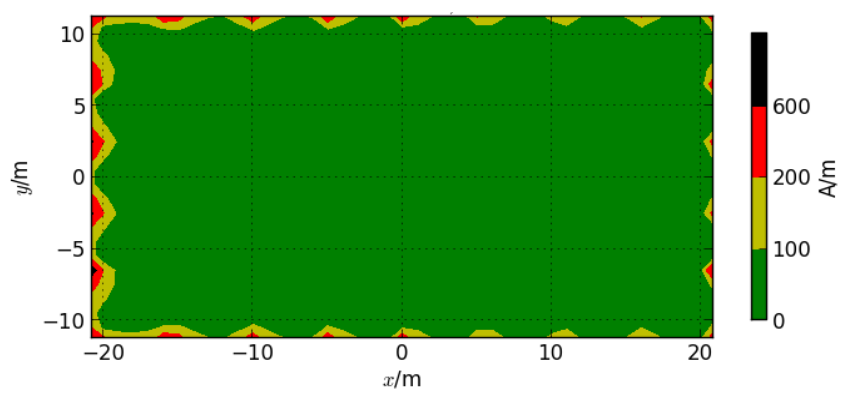

Figure 17 : Magnetic field at intermediate floor level $(\mathrm{z}=\mathbf{1 4 . 6} \mathrm{m}$ floor $)$

\section{CONCLUSION}

Local and partial measurement data clearly outline a building low-pass filter behavior which cannot be taken into account using a numerical single mesh model. However, we managed to determine a majoring error factor to extrapolate with good confidence the magnetic field levels calculated considering a more realistic lightning strike. The obtained levels have been compared to actual standards. These computed magnetic field levels are still larger that the ones expected in reality and a more realistic building model is needed to get more accurate levels.

In a future study, we plan to use surface impedance measurements of the walls to define an equivalent thin panel model that could reproduce the low-pass filter behavior of the real building and thus get more accurate waveforms and levels. 


\section{REFERENCES}

[1] I.A. Metwally, F.H. Heidler, "Reduction of lightning-induced magnetic fields and voltages inside struck double-layer grid-like shields", IEEE Trans. On EMC, Vol. 50, NO. 4, Nov 2008.

[2] J. Raimbourg, S. Bazzoli, J. Gazave, O. Peyssoneaux, M. Mardiguian, "Champ électromagnétique induit par la foudre sur un bâtiment faradisé : modélisation numérique et validation sur une maquette", CEM 2011, Limoges.

[3] W. Zhang, Z. Zhao, S. Gu, N. Xiang, "Analysis of magnetic fields radiated by lightning strikes to a building", $7^{\text {th }}$ asia-pacific international conference on lightning, Nov. 2011, China.

[4] F. Issac, B. Michielsen, E. Bachelier, D. Prost, C. Miry, E. Amador, C. Trouilloud, "Protection against lightning of reinforced concrete buildings", ICOLSE 2013, unpublished.

[5] HIFREQ and FFTSES user's manuals, Safe engineering services and technologies Ltd, Montreal, Canada, 2000.
[6] CST-Microwave Studio 2012, user's manual.

[7] E. Bachelier, F. Issac, S. Bertuol, J.P. Parmantier, "Electromagnetic numerical study for optimizing the lightning protection system of the VEGA launching pad", ICLP 2010, Cagliari, Italy.

[8] Protection against lightning - Part 1 : General principles, standard IEC 62305-1, Dec. 2010.

[9] Nuclear power plants - Instrumentation and control important to safety Requirements for electromagnetic compatibility testing, IEC 62003 ed1.0, Mar. 2009

[10] D. Prost, F. Issac, T. Volpert, W. Quenum, Parmantier "LightningInduced Current Simulation Using RL Equivalent Circuit: Application to an Aircraft Subsystem Design", IEEE Transactions on Electromagnetic Compatibility, vol.5, 2, 2013

[11] A. Metwally, F. H. Heidler, "Reduction of lightning-induced magnetic fields and voltages inside struck double-layer grid like shields", IEEE Transactions on Electromagnetic Compatibility, vol.50, 2008 